\title{
Mitigation of Load Frequency Fluctuation Using a Centralized Pitch Angle Control of Wind Turbines
}

\author{
Liu Junqiao *, Marwan Rosyadi *, Rion Takahashi *, Junji Tamura *, Tomoyuki \\ Fukushima **, Atsushi Sakahara **, Koji Shinya **and Kazuki Yosioka **
}

\begin{abstract}
In this paper an application of centralized pitch angle controller for fixed speed wind turbines based wind farm to mitigate load frequency fluctuation is presented. Reference signal for the pitch angle of each wind turbine is calculated by using proposed centralized control system based on wind speed information. The wind farm in the model system is connected to a multi machine power system which is composed of 4 synchronous generators and a load. Simulation analyses have been carried out to investigate the performance of the controller using real wind speed data. It is concluded that the load frequency of the system can be controlled smoothly.
\end{abstract}

\section{Keywords: Load Frequency Control, Pitch Controller, Wind Farm}

\section{Introduction}

Due to the limitation of the fossil fuels and their harmful influent on the environment, recently the concentration on renewable energy sources has been increasing all over the world. Wind energy is one of promising renewable energy resource to be converted into electrical power compared to the others resources such as biogas, solar, and geothermal. Global Wind Energy Council (GWEC) has predicted that global wind power generation capacity will reach to $459 \mathrm{GW}$ and new capacity of 62.5 GW will be added to the global total at the end of 2015 [1]. Moreover, many countries have been planning to use $10 \%$ of their electricity demand from wind energy until 2020 [2].

It is well known that the wind generator output can have an influence on a power system frequency due to wind speed variations. The frequency in the power system is stable when the electrical demand plus the electrical losses equal the electrical generation in the system. An imbalance between power generation and demand can cause deviation on the grid frequency. As the frequency stability is an essential aspect of the power system security. The power system operators have to revise their grid connection requirements especially about reliability of their power system [3]. Therefore it is important to design a suitable control strategy for smoothing power production of wind farm when it is connected to main grid.

\footnotetext{
* Department of Electrical Engineering, Kitami Institute of Technology,Japan(dalianliujungiao@126.com,marwanrosyadi@yahoo .co.id,rtaka@mail.kitami-it.ac.jp,tamuraj@mail.kitami-it.ac.jp)

** Hokkaido Electric Power Co, Japan

Received 08 January 2013; Accepted 15 February 2013
}

Traditionally, the frequency oscillation is damped by using conventional power plants with synchronous generators, which are equipped with power system stabilizers. Power system stabilization with synchronous generators is an established technology, which is applied all over the world [4].

In general, the Fixed Speed Wind Turbines with Squirrel Cage Induction Generator (FSWT-SCIG) is most widely used in wind farms. This type of wind turbine is very popular and it has the advantages of mechanical simplicity, low specific mass, robust construction, and low cost [5]. However, the controller of this type wind turbine is only equipped with conventional blade pitch angle. The conventional pitch controller is used, in general, to maintain the output power of the wind generator at its rated level when the wind speed is over the rated speed. However the output power from the wind farm cannot be controlled smoothly by using the conventional method.

Some methods have been proposed in order to smooth wind power fluctuations. In [6, 7], a flywheel energy storage system is proposed for smoothing wind farm output, but the flywheel energy system has complicated control strategy. Utilization of Flexible AC Transmission System (FACT) devices such as Static Synchronous Compensator (STATCOM), Static Var Compensator (SVC), and Unified Power Flow Controller (UPFC) have become the better choice due to their advantages of flexible power flow control and good damping solution for power system dynamic oscillations [8, 10]. Superconducting Magnetic Energy Storage (SMES) and Battery Energy Storage System (BESS) integrated with a STATCOM are a very 
good system for wind power smoothing due to its response speed and high efficiency [11-13]. However, the system overall cost will increase when the devices are installed in the wind farm.

SMA (Simple Moving Average) and EMA (Exponential Moving Average) methods have been proposed to control pitch controller of the FSWT-ICIG based wind farm in order to reduce load frequency fluctuation [14]. In this concept, the reference output of wind generator is determined by using moving average of wind speed. Therefore, the oscillating components in the wind turbine output can be smoothed. However, the wind farm is operated by using the conventional pitch controller when the load is heavy during daytime and the farm is operated by the proposed controller when the load is light during midnight.

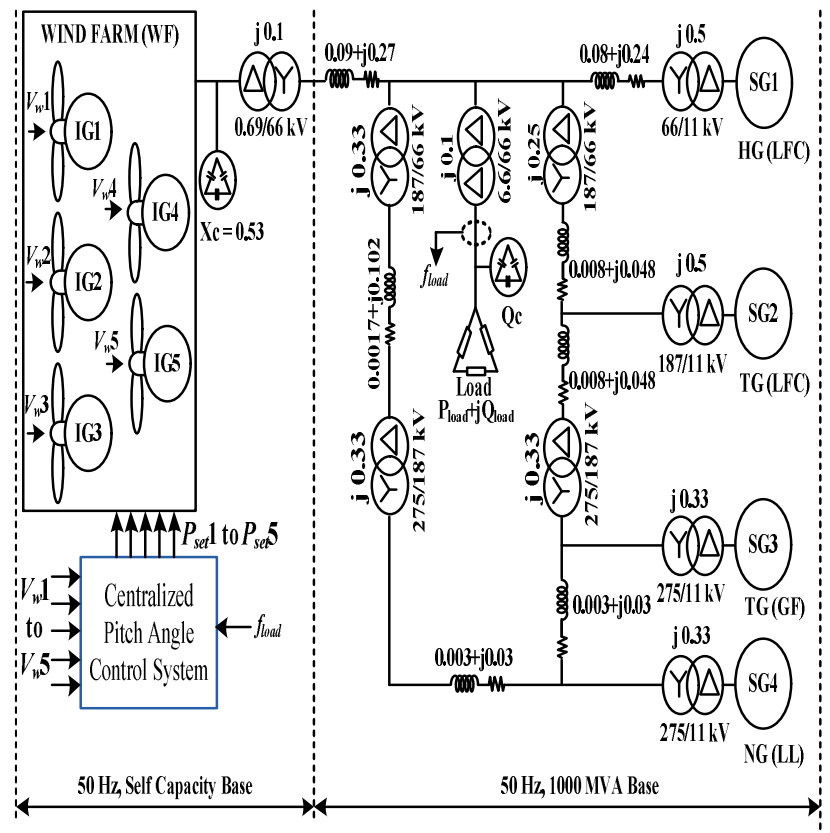

Fig. 1. Model System

In this paper, a novel pitch control system is proposed to smooth wind farm output power. The control system is designed in the central management system, which determines the power reference set point for each wind generators. By this system, the output power can be controlled smoothly as well as mitigate load frequency fluctuation. The proposed method has the advantage of low cost compared with other smoothing methods using energy storage systems because the pitch control system is equipped in most present wind turbines. In addition, the pitch control method can be simply switched from the conventional method to the proposed one. The simulation studies have been performed using PSCAD/EMTDC.
Table1. Parameters of Generators

\begin{tabular}{|c|c|c|c|c|}
\hline \multicolumn{5}{|c|}{ Induction Generator } \\
\hline & \multicolumn{4}{|c|}{ Squirrel cage type (IG1 to IG 5) } \\
\hline MVA & 10 (each) & \multicolumn{3}{|c|}{20 (each) } \\
\hline $\mathrm{R}_{1}[\mathrm{pu}]$ & \multicolumn{4}{|l|}{0.01} \\
\hline $\mathrm{X}_{1}[\mathrm{pu}]$ & \multicolumn{4}{|l|}{0.1} \\
\hline $\mathrm{X}_{\mathrm{m}}[\mathrm{pu}]$ & \multicolumn{4}{|l|}{3.5} \\
\hline $\mathrm{R}_{2}[\mathrm{pu}]$ & \multicolumn{4}{|l|}{0.01} \\
\hline $\mathrm{X}_{2}[\mathrm{pu}]$ & \multicolumn{4}{|l|}{0.12} \\
\hline $2 \mathrm{H}[\mathrm{sec}]$ & \multicolumn{4}{|l|}{1.5} \\
\hline \multicolumn{5}{|c|}{ Synchronous Generator } \\
\hline & \multirow{2}{*}{$\begin{array}{l}\text { Salient pole type } \\
\text { (SG1) }\end{array}$} & \multicolumn{3}{|c|}{ Cylindrical type } \\
\hline & & SG2 & SG3 & SG4 \\
\hline MVA & 300 & 200 & 300 & 300 \\
\hline $\mathrm{Xd}[\mathrm{pu}]$ & 1.2 & \multicolumn{3}{|l|}{2.11} \\
\hline $\mathrm{Xq}[\mathrm{pu}]$ & 0.7 & \multicolumn{3}{|l|}{2.02} \\
\hline $\mathrm{H}[\mathrm{sec}]$ & 5 & \multicolumn{3}{|l|}{4} \\
\hline
\end{tabular}

\section{Power System Model}

The model system used in the simulation analyses is shown in Fig. 1. The model system consists of a wind farm (WF), a hydro power plant, SG1, with a salient pole synchronous generator (HG), two thermal power plants, SG2 and SG3, with cylindrical rotor synchronous generator (TG), a nuclear power plant, NG, with cylindrical rotor synchronous generator (SG4), and a static load rated at 1000 MVA. SG1 and SG2 are operated under Load Frequency Control (LFC), SG3 is under Governor Free (GF) and SG4 is under Load Limit (L.L). LFC is used to control frequency fluctuations with a long period more than a few minutes, and GF is used to control fluctuations with a short period less than a minute. LL is used to output constant power.

The wind farm consists of five fixed speed wind turbine type with induction generators (IG1 to IG5). XC and QC are capacitor banks. XC is used at the terminal of wind farm to compensate the reactive power demand at steady state. QC issued at the terminal of load to compensate the voltage drop due to the impedance of transmission lines. Core saturations of induction generator and synchronous generators are not considered in the analysis. Parameters of IG and SG are shown in Table I.

The centralized pitch angle control system is used to control the blade angle all of the wind turbines. The wind speed information from each wind turbines (Vw1 to Vw5) and load frequency (fload) are collected in order to obtain the power reference for each wind turbine (Pset1 to Pset5). 


\section{Wind Turbine Model}

In this paper, the MOD-2 characteristic is used for the wind turbine model [15]. Modeling expression of MOD-2 is given as follows. The captured power from the wind can be obtained from Eq. (1). Tip speed ratio, $\lambda$, and power coefficient, CP, can be expressed as Eq. (2) and Eq. (3). Since CP is expressed in feet and mile, $\Gamma$ is corrected as Eq. (4).

$$
\begin{gathered}
P_{w t b}=\frac{1}{2} \rho C_{P}(\lambda) \pi R^{2} V_{w}^{3} \\
\lambda=\frac{\omega_{w t b} R}{V_{w}} \\
C_{P}(\lambda)=0.5\left(\Gamma-0.022 \beta^{2}-5.6\right) e^{-0.17 \Gamma} \\
\Gamma=\frac{R}{\lambda} \cdot \frac{3600}{1609}
\end{gathered}
$$

The torque coefficient and the wind turbine torque are shown as follows.

$$
\begin{gathered}
C_{t}(\lambda)=\frac{C_{P}(\lambda)}{\lambda} \\
\tau_{M}=\frac{1}{2} \rho C_{t}(\lambda) \pi R^{3} V_{w}^{2}
\end{gathered}
$$

where, Pwt is wind turbine output [W], $\mathrm{R}$ is the radius of the blade [m], $\omega \mathrm{wtb}$ is wind turbine angular speed $[\mathrm{rad} / \mathrm{s}]$, $\beta$ is blade pitch angle [deg], $\mathrm{Vw}$ is wind speed [m/s], $\rho$ is air density $[\mathrm{kg} / \mathrm{m} 3]$, and $\tau \mathrm{M}$ is wind turbine output torque $[\mathrm{Nm}]$.

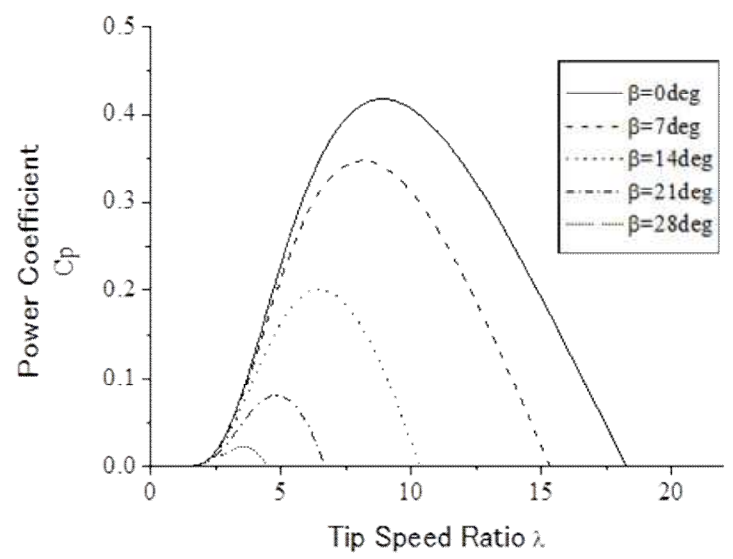

Fig. 2. Wind Turbine characteristic

$\mathrm{Cp}$ is the power factor, and the parameters which characterize the windmill. The power coefficient $\mathrm{Cp}$ characteristic graph according to the convergence ratio of $\lambda$ is shown in Fig 2.

\section{Synchronous Generator Model}

\subsection{Governor Model}

The governor is a device that automatically adjusts the generator output and the rotational speed of the turbine. When the load is constant, the turbine is operated at a constant rotational speed. However, when the load changes, balance between the generator output and the load is not maintained, and then the rotational speed changes. When the load is removed, the governor detects the increase of the rotational speed and the valve is closed rapidly, and thus an abnormal speed increase of the generator is prevented.

The governor models for SG 1 to SG4 used in this simulation are shown in Fig. 3 and Fig. 4 [16]. The values of $65 \mathrm{M}$ and $77 \mathrm{M}$ are shown in Table II, where, PLM for SG3 is set 5[\%] and for SG4 $-20[\%]$ because the nuclear generator output (SG4) is constant output (L.L, load limit operation).

where,

Sg: the revolution speed deviation $[\mathrm{pu}]$

65M: the initial output [pu]

77M: the load limits $(65 \mathrm{M}+$ rated MW output $\times$ PLM [\%]).

PLM: the spare governor operation [\%]

Pm: the turbine output [pu]

Sg for SG1 and SG2 is set zero because these generators are operated under LFC to control frequency fluctuations with a long period.

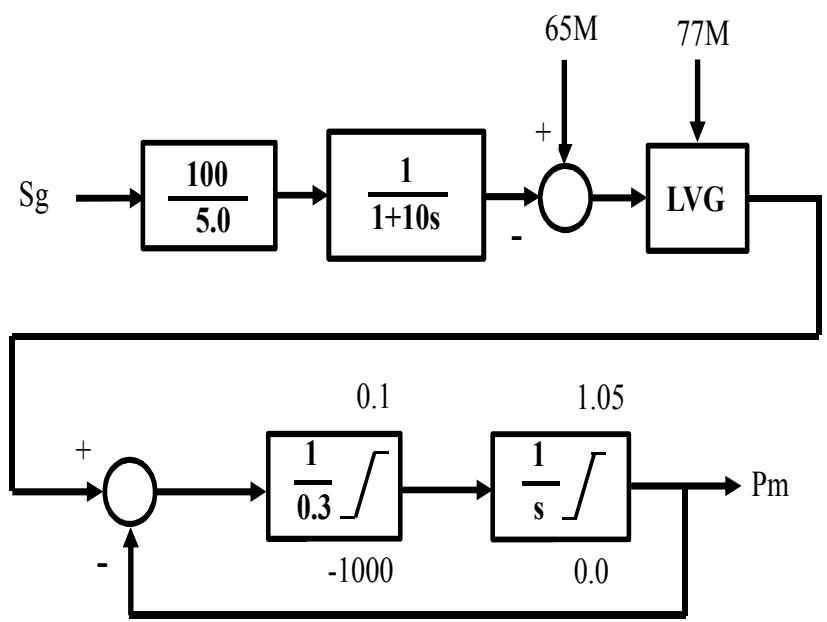

Fig. 3. Hydro governor model 

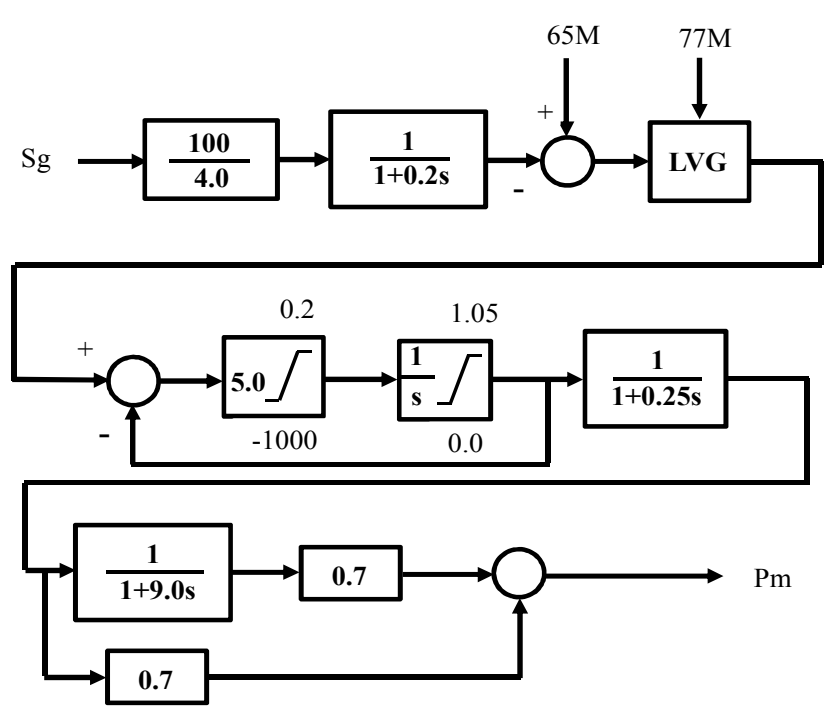

Fig. 4. Thermal and nuclear governor model

Table 2. Values of $65 \mathrm{M}$ and $77 \mathrm{M}$

\begin{tabular}{|l|l|l||l|l|l|}
\hline \multicolumn{2}{|l||}{ SG1(Hydro) } & \multicolumn{3}{|l|}{ SG2(Thermal) } \\
\hline $\begin{array}{l}\text { Frequency } \\
\text { control }\end{array}$ & $65 \mathrm{M}$ & $77 \mathrm{M}$ & $\begin{array}{l}\text { Frequency } \\
\text { control }\end{array}$ & $65 \mathrm{M}$ & $77 \mathrm{M}$ \\
\hline LFC & $\begin{array}{l}\text { LFC } \\
\text { signal }\end{array}$ & 1 & LFC & $\begin{array}{l}\text { LFC } \\
\text { signal }\end{array}$ & 1 \\
\hline \hline SG3(Thermal) & \multicolumn{1}{|l||l|}{ SG4(Nuclear) } \\
\hline $\begin{array}{l}\text { Frequency } \\
\text { control }\end{array}$ & $65 \mathrm{M}$ & $77 \mathrm{M}$ & $\begin{array}{l}\text { Frequency } \\
\text { control }\end{array}$ & $65 \mathrm{M}$ & $77 \mathrm{M}$ \\
\hline G.F & 0.8 & 0.84 & L.L & 0.96 & 0.8 \\
\hline
\end{tabular}

\subsection{Automatic voltage regulator (AVR)}

To keep the voltage of the synchronous generator constant, AVR is needed. In this simulation analyses, the AVR is expressed by a first order time delay system. AVR model is shown in Fig. 5. Parameters of AVR are shown in Table3.

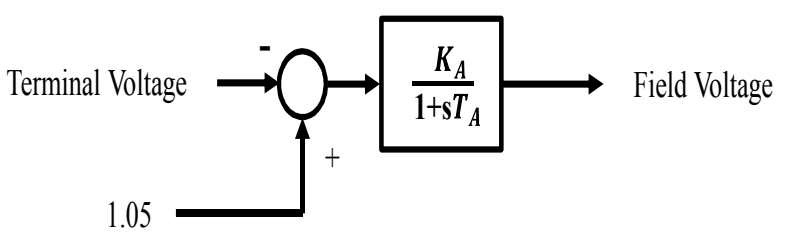

Fig. 5. AVR model

Table 3. Parameters of AVR

\begin{tabular}{|l|l|}
\hline Gain ${ }^{K_{A}}$ & 400 \\
\hline Time Constant ${ }^{T_{A}}[\mathrm{sec}]$ & 0.02 \\
\hline
\end{tabular}

\subsection{Load Frequency Control Model}

The Load Frequency Control (LFC) sends the output value signal to each power plant after detecting frequency deviations. Then, governor output value $(65 \mathrm{M})$ of each power plant is changed by LFC signal, and the power plant output is changed. The frequency deviation is input into Low Pass Filter (LPF) to remove fluctuations with short period because the LFC is used to control frequency fluctuations with a long period. The LFC model is shown in Fig. 6.

where,

Tc : $\quad$ LFC period $=200[\mathrm{~s}]$

$\omega c: \quad$ LFC frequency $=1 / \mathrm{Tc}=0.005[\mathrm{~Hz}]$

$\zeta: \quad$ damping ratio $=1$.

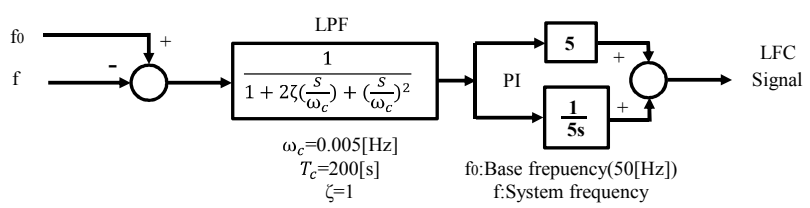

Fig. 6. LFC model

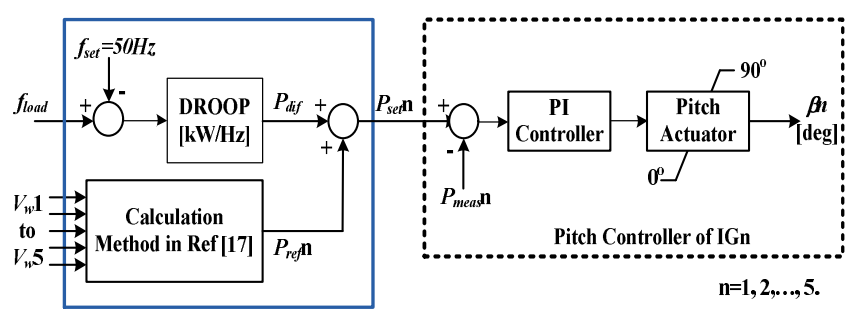

Fig. 7. The Centralized pitch angle control

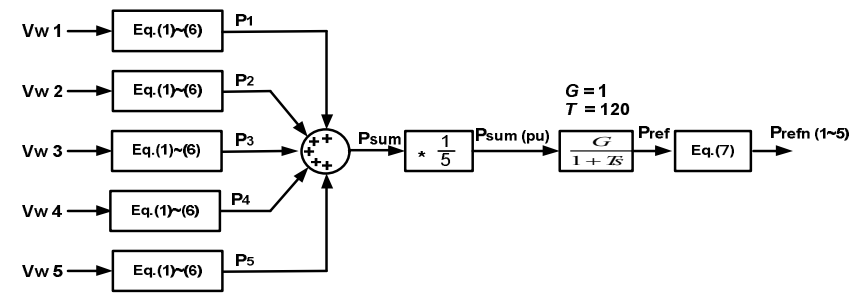

Fig. 8. Calculation method

\section{Centralized Pitch Angle Control}

Details of the centralized pitch angle control system are shown in Fig.7. In order to damp load frequency oscillations, the wind turbine power output is controlled in such way by increasing and reducing its power output when the load frequency is low and high. If the frequency of the load system (fload) deviates from the frequency set point (fset) of $50 \mathrm{~Hz}$, the frequency error causes a power signal 
Pdiff. The Pdiff is added to the each power reference (Prefn) in order to obtain the power set point (Psetn). The control loop of the pitch actuator is represented by a firstorder transfer function with an actuator time constant $(\mathrm{Ts}=5)$ and the pitch rate limiter of $10 \mathrm{deg} / \mathrm{s}$. A classical PI controller is used to manage tracking error. In Fixed Speed Wind Turbine the pitch controller is used to regulate power output of IG under power set point.

In this paper, the power reference for each wind turbine is calculated using the method as described in Ref. [17]. The block diagram of the method is shown in Fig. 8. The power captured of wind turbines (P1, P2, P3, P4, and P5) are calculated by using eq. 1 to eq. 6 based on the wind speed information from each wind turbines (Vw1 to Vw5). The wind turbine power outputs (P1, P2, P3, P4, and P5) are added in order to obtain the total power output of the wind turbine (Psum). The low pass filter is used for smoothing power output of wind turbines. By using eq. 7 the power references of each wind turbine is obtained.

$\operatorname{Prefn}(\mathrm{n}=1,2,5)=$ Pref $\times \frac{P n(n=1,2,5)}{P 1+P 2+p 3+p 4+p 5}$

In order to mitigate grid frequency oscillations, pitch controller of the wind turbine controls increasing and reducing the generator power output when the grid frequency is low and high, respectively. Fig. 9 shows the frequency control loop system of the wind turbine. If the frequency of the power system (fload) deviates from the set point, (fset), the frequency error causes a power signal Pdiff, which acts as set point on the closed power control loop contributing to the power error signal.

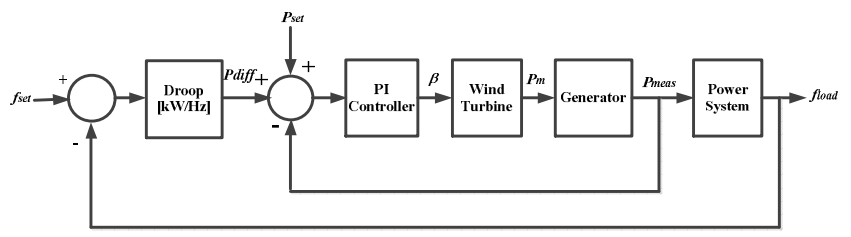

Fig. 9. The frequency control loop of the wind turbine

\section{Simulation Results}

Simulation analyses have been carried out to investigate the performance of the proposed pitch control system. The simulation has been performed by using PSCAD/EMTDC with simulation time is 600 [sec]. The real wind speed data used in the simulation analysis is shown in Fig. 10. Figs. 11 to 15 show the pitch angle responses of wind turbines obtained from conventional and proposed pitch control systems where "DLP pitch" means the proposed system. Fig. 16 shows power output of the wind farm. It is seen that output power is controlled smoothly by using the new proposed method. Therefore the frequency fluctuation of the power system can be damped effectively as shown in Fig. 17.

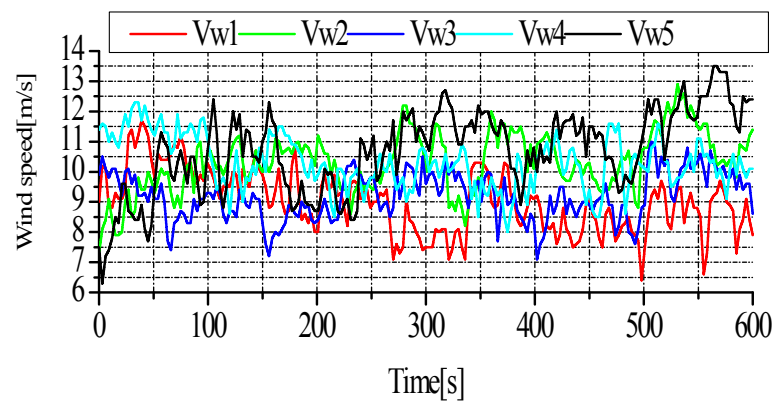

Fig. 10. Wind speed data

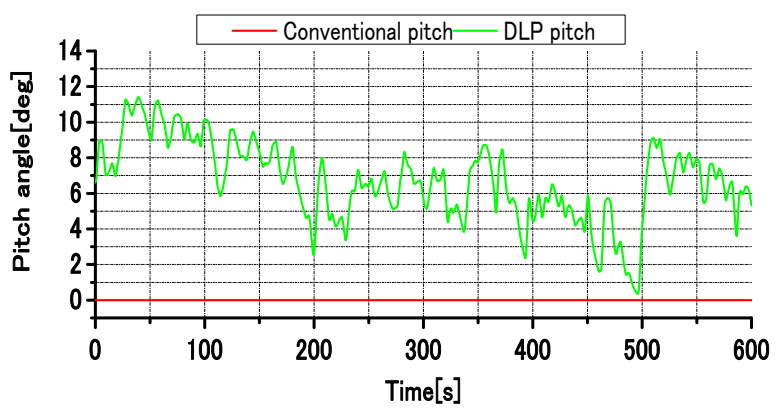

Fig. 11. Pitch angle response of IG1

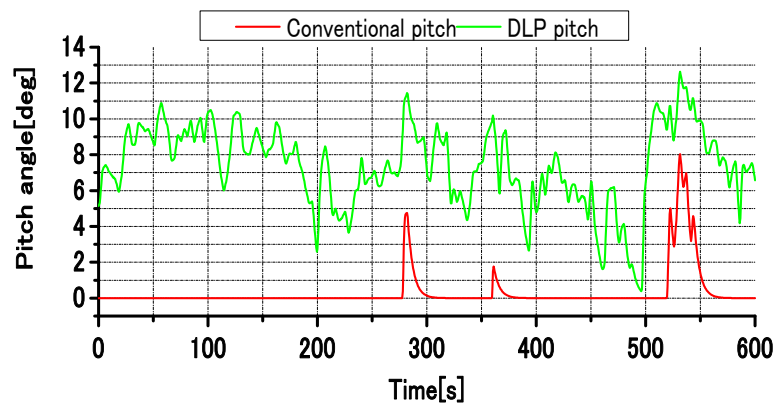

Fig. 12. Pitch angle response of IG2

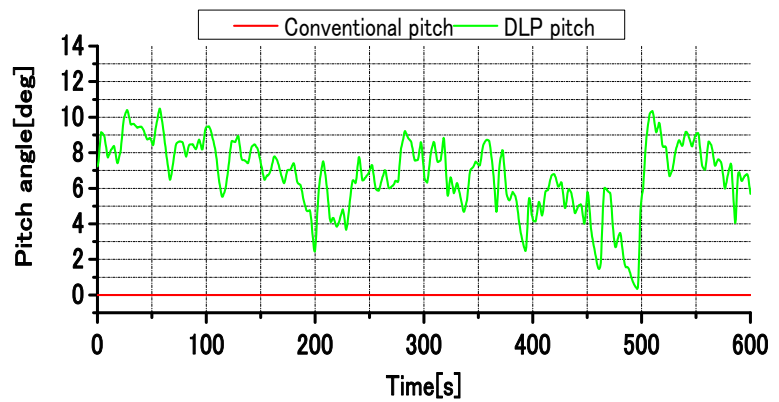

Fig. 13. Pitch angle response of IG3 


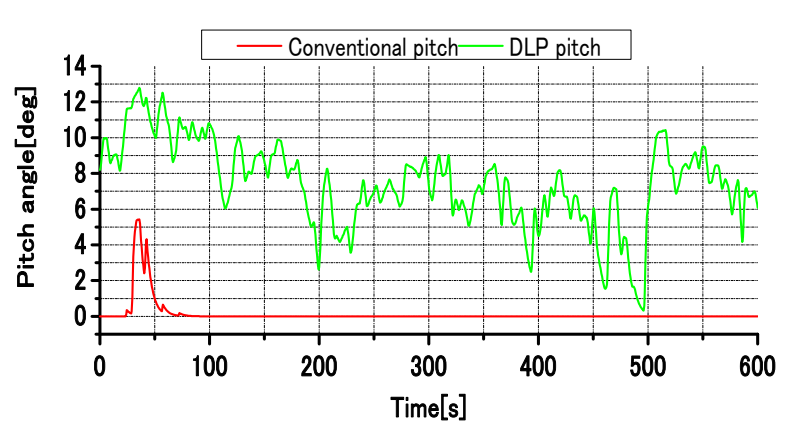

Fig. 14. Pitch angle response of IG4

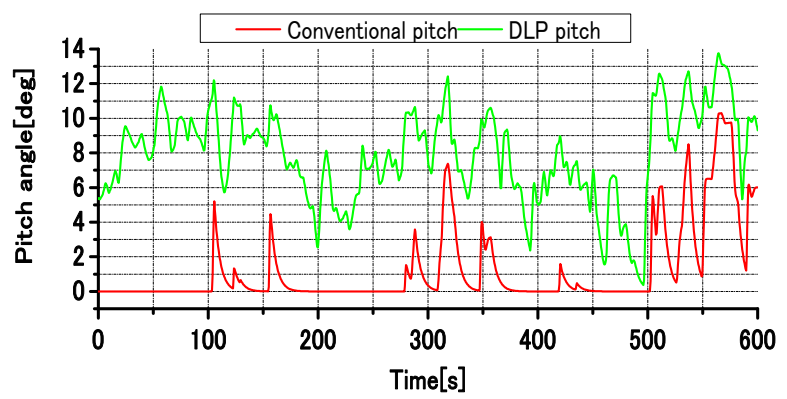

Fig. 15. Pitch angle response of IG5

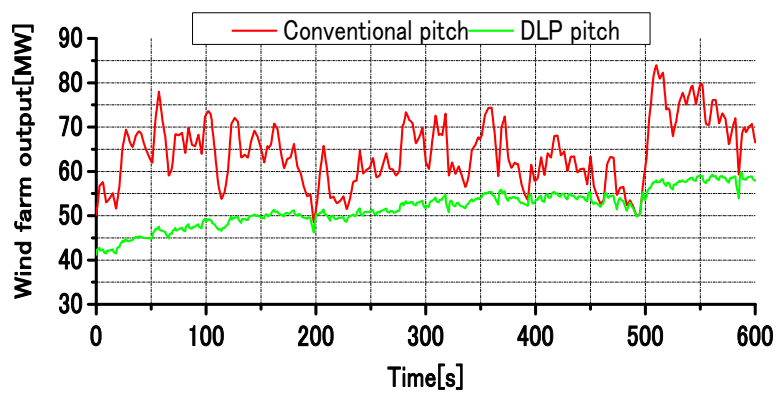

Fig.16. Power output of the wind farm

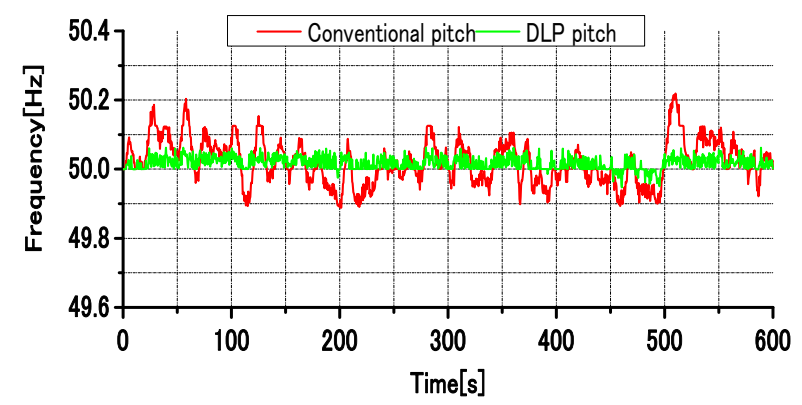

Fig. 17. Frequency response of the power system

\section{Conclusion}

New pitch control system of wind farm for smoothing power production has been presented. Simulation analyses have been carried out to investigate the performance of the proposed method with using real wind speed. The comparison between conventional and proposed pitch control systems is also investigated. It can be concluded that power output of the wind farm can be controlled smoothly. Hence the frequency fluctuation can be damped effectively.

\section{References}

[1] The Global Wind Energy Council (GWEC), Global wind report 2010, April 2011. [Online]. Available: http://www.gwec.net/

[2] Ahmet Serdar Yilmaz, Zafer Ozer, "Pitch Angle Control in Wind Turbines Above the Rated Wind Speed by Multi-Layer Perceptron and Radial Basis Function Neural Networks", Expert Systems with Applications, Vol. 36, pp. 9767-9775, 2009.

[3] Jauch C, Matevosyan J, Ackermann T, Bolik S., International comparison of requirements for connection of wind turbines to power systems, Wind Energy, Vol. 8. No. 3, pp. 295-306, Jul 2005.

[4] Kundur P. Power system stability and control. New York: McGraw-Hill, Inc., 1994

[5] Thomas Ackermann, Wind power in power system, UK: John Wiley \& Sons, 2005.

[6] R. Cardenaes, R. Pena, G. Asher, J. Clare, "Power Smoothing in Wind Generation System Using a Sencorless Vector Controlled Induction Machine Driving a Flywhell," IEEE Transaction on Energy Conversation, Vol 19. Issue. 1. Pp. 206-216, 2004.

[7] F. Hardan, J. A. M. Bleijs, R. Jones, P. Bromley, A. J. Ruddel, "Application of a Power Controlled Flywheel Drive for Wind Power Conditioning in a Wind/Diesel Power System," The $9^{\text {th }}$ International conference on Electrical Machines and Drive, paper No. 468, pp. 65 - 70. 1999.

[8] S. M. Muyeen, M. A. Mannan, M. H. Ali, R. Takahashi, T. Murata, and J. Tamura, "Stabilization of Wind Turbine Generator System by STATCOM," IEEJ Trans. Power Energy, vol. 126, no. 10, pp.1073-1082, Oct. 2006.

[9] S. G. Bharathi Dasan, S. Ravichandran, R. P. Kamesh Kumudini Devi, "Steady-state Analysis of Grid Connected WECS using FACTS controller", in Proc. International Conference on Emerging Trends in Electrical and Computer Technology (ICETECT),pp. 127-132. Mar. 2011.

[10] L. Gyugyi: "Unified Power Flow Control Concept for Flexible ac Transmission System", in Proc. Inst. Elect. Eng. C. Vol. 139. No. 4, pp. 323-331, 1992.

[11] M.R.I.Sheikh, S.M. Muyeen, R.Takahashi, J.Tamura, "Smoothing Control of Wind Generator Output Fluctuations by PWM Voltage Source Converter and Chopper Controlled SMES," European Trans. Electrical Power, Vol. 21, Issue-1, pp. 680-697, Jan. 2011.

[12] L. Zhang, C. Shen, M. L. Crow, L. Dong, S. Pekarek, and S. Atcitty, "Performance Indices for the Dynamic Performance of FACTS and FACTS with Energy Storage," Elect. Power Compon. Syst., vol. 33, no. 3, pp. 299-314, Mar. 2005.

[13] S. M. Muyeen, M. H. Ali, R. Takahashi, T. Murata, and J. Tamura, "Wind Generator Output Power Smoothing and Terminal Voltage Regulation by Using STATCOM/BESS," The IEEE Powertech 2007 Conference, Ref No. 258, Lausanne, Switzerland.

[14] T. Yamazaki et al., "Smoothing Control of Wind Generator Output Fluctuations by New Pitch Controller", IEEJ Trans. PE, Vol. 129, No. 7, pp .880-888, Jul 2009.

[15] S. M. Muyeen, J. Tamura, and T. Murata, Stability augmentation of a grid connected wind farm, Green Energy and Technology, London, Springer-Verlag, 2009.

[16] IEE of Japan, Technical Reports Vol.754: Standard Models of Electrical Power System, pp. 40-43 
[17] Liu Junqiao, Rion Takahashi, Junji Tamura, Tomoyuki Fukushima, Atsushi Sakahara, Koji Shinya, "A New Control Strategy for Smoothing Frequency Fluctuation due to Wind Generation," 2011 International Conference on Electrical Machines and Systems (ICEMS2011), RE-08, August 2011.

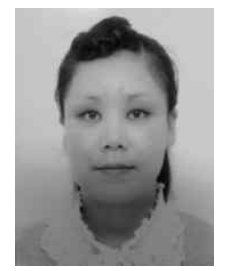

Liu Junqiao received B.S degree in electrical engineering from Northeast Dianli University, China and M. Eng. Degree from Kitami institute of Technology, Japan in 2008 and 2011, respectively. Presently she is working towards her Ph.D Degree at the Kitami Institute of Technology, Kitami, Hokkaido, Japan. Her research interests are emerging energy systems and electric machines.

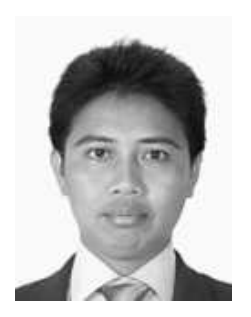

Marwan Rosyadi received Sarjana Teknik (equivalent to B.Sc. degree) from Adhi Tama Institute of Technology Surabaya and M.Eng. degree from Sepuluh Nopember Institute of Technology, Indonesia, in 2004 and 2006 respectively, all in Electrical Engineering. Presently he is working towards his Ph.D Degree at the Kitami Institute of Technology, Kitami, Hokkaido, Japan. His research interests are stability and control of power system including wind generator.

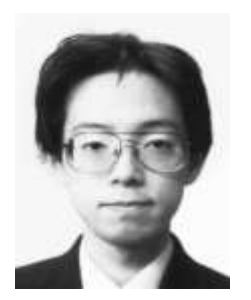

Rion Takahashi received the B.Sc. Eng. and Dr. Eng. Degrees from Kitami Institute of Technology, Japan, in 1998 and 2006 respectively, all in Electrical and Electronic Engineering. Now he is working as Associate Professor in Department of Electrical and Electronic Engineering, Kitami Institute of Technology. His major research interests include analysis of power system transient, FACTS and wind energy conversion system. He is a member of IEEE.

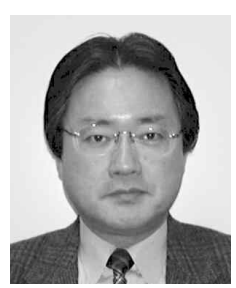

Junji Tamura received his B. Sc. Eng. Degree from Muroran Institute of Technology, Japan, in 1979 and M.Sc. Eng. and Dr. Eng. degrees from Hokkaido University, Japan, in 1981 and 1984 respectively, all in electrical engineering. $\mathrm{He}$ became a lecturer in 1984, an Associate Professor in 1986, and a Professor in 1996 at the Kitami Institute of Technology, Japan. Currently he is a Vice President of the Kitami Institute of Technology. Dr. Tamura is a Senior Member of the IEEE Power Engineering Society.

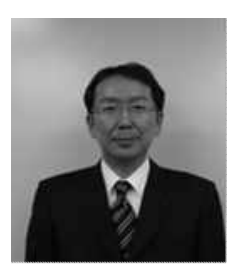

Tomoyuki Fukushima graduated from Hokkaido University (Graduate School of Electrical Engineering) in March 1988, and then he joined the Hokkaido Electric Power Co., Inc. Presently he is a Manager of the Engineering Department. His main field is the planning of power system.

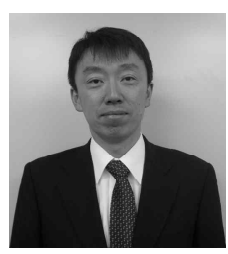

Atsushi Sakahara graduated from Waseda University (Graduate School of Science and Engineering) in March 1994, and then he joined the Hokkaido Electric Power Co.,Inc. Presently he is working in the Engineering Department. His main field is the planning of power system.

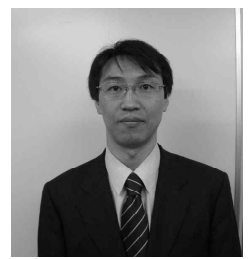

Koji Shinya graduated from Tohoku University (Graduate School of Electrical and Communication Engineering) in March 1997, and then he joined the Hokkaido Electric Power Co., Inc. Presently he is working in the Power Network Center. His main field is the planning of power system.

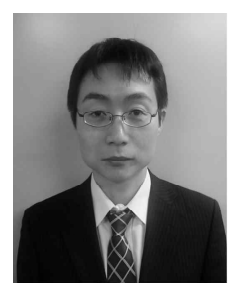

Kazuki Yoshioka graduated from Kushiro National College of Technology (Department of Electronic Engineering) in March 1994, and then he joined the Hokkaido Electric Power Co., Inc. Presently he is working in the Engineering Department. His main fiel is the planning of power system. 